\title{
Sexting: a espetacularização da sexualidade
}

\author{
Suzana da Conceição Barros \\ Universidade Federal do Rio Grande (FURG) \\ suzinhab@yahoo.com.br \\ Paula Regina Costa Ribeiro \\ Universidade Federal do Rio Grande (FURG) \\ pribeiro@vetorial.net \\ Raquel Pereira Quadrado \\ Universidade Federal do Rio Grande (FURG) \\ raquelquadrado@hotmail.com
}

\section{Resumo}

O termo sexting foi criado nos Estados Unidos da América e significa envio de mensagens de conotação sexual. A prática consiste em utilizar as diversas tecnologias digitais (celulares, internet etc.) presentes em nossa sociedade para expor a sexualidade. Neste texto, são analisadas algumas reportagens, notícias, blogs, comentários, postados na internet, a fim de investigar as enunciações sobre a espetacularização da sexualidade. Para tanto, a internet é utilizada como ferramenta para a produção dos dados. Ao realizar a análise do material empírico, foram percebidos alguns afrouxamentos nas fronteiras entre o que é considerado de âmbito público e privado, o que pode ser entendido como uma condição de possibilidade para a emergência do sexting. Os/As adolescentes estão utilizando as tecnologias digitais para realizarem a espetacularização do eu, ou seja, para ganharem visibilidade e tornaremse a personalidade do momento. Junto a isso, é crescente o número de sujeitos que se preocupam em examinar e esquadrinhar a vida alheia. Por fim, é necessário ressaltar o quão importante são os estudos sobre o sexting, pois é uma prática recente, que se instalou em nossa sociedade e que traz algumas reconfigurações no entendimento da sexualidade.

Palavras-chave: Sexting. Sexualidade. Tecnologias digitais.

\section{Sexting: the spectacularization of sexuality}

\author{
Abstract \\ Sexting is a term that was created in the United States and refers to the act of sending \\ messages of sexual content. Sexting consists in the use of different digital technologies (cell \\ phones, internet, etc.) present in our society, in order to expose the sexuality. In this article, \\ it was analyzed some reports, news, blogs, comments, posted on the Internet in order to \\ investigate the statements about the spectacularization of sexuality. Thus, it was used the
}


internet as a tool for data producing. While performing the analysis of the empirical data, it was noticed some loosening in boundaries between what is considered the public and private scope, which can be understood as a condition of possibility for the emergence of the sexting. Adolescents are using digital technology to make the spectacularization of the self, i.e. to gain visibility and become the outcoming personality. Along with this comes a growing number of individuals who are concerned to examine and scrutinize the lives of others. It was considered to be important to focus on the studies of sexting, once it was understood as a recent practice, that was installed in our society and is bringing some reconfigurations in the understanding of sexuality.

Keywords: Sexting. Sexuality. Digital technologies.

\section{Sexting: la espectacularización de la sexualidad}

\section{Resumen}

El término sexting se creó en Estados Unidos de América y significa envío de mensajes de connotación sexual. La práctica consiste en utilizar las diversas tecnologías digitales (celulares, internet, etc.) presentes en nuestra sociedad para exponer la sexualidad. En este texto, se analizan algunos reportajes, noticias, blogs, comentarios, publicados en internet, a fin de investigar las enunciaciones sobre la espectacularización de la sexualidad. Para esto, internet se utiliza como herramienta para la producción de los datos. Al realizar el análisis del material empírico, se percibieron algunos ablandamientos en las fronteras entre lo que se considera de ámbito público y privado, lo que puede entenderse como una condición de posibilidades para el surgimiento del sexting. Los/Las adolescentes están utilizando las tecnologías digitales para realizar la espectacularización del yo, es decir, para ganar visibilidad y convertirse en la personalidad del momento. Junto a esto, es creciente el número de sujetos que se preocupan en examinar y escudriñar la vida ajena. Por fin, es necesario resaltar cuán importantes son los estudios sobre el sexting, pues es una práctica reciente, que se instaló en nuestra sociedad y que trae algunas reconfiguraciones en el entendimiento de la sexualidad.

Palabras clave: Sexting. Sexualidad. Tecnologías digitales.

\section{Contextualizando o estudo}

Este artigo tem como objetivo analisar alguns materiais - reportagens, comentários e matérias -, postados na internet, a fim de investigar as enunciações sobre a espetacularização da sexualidade.

O sexting emerge a partir do século XXI, e pode ser entendido como uma prática sociocultural, que consiste em enviar para alguém fotos, vídeos e mensagens, de conotação sexual, através das diversas tecnologias digitais. Nesse sentido, essa prática tem como objetivo a exibição da sexualidade. 
Neste estudo, entendemos a sexualidade como um dispositivo histórico, que articula prazeres, poderes e saberes, com o objetivo de responder a uma urgência. Segundo Michel Foucault (2007):

A sexualidade é nome que pode dar a um dispositivo histórico: não à realidade subterrânea que se aprende com dificuldade, mas à grande rede da superfície em que a estimulação dos corpos, a intensificação dos prazeres, a incitação ao discurso, a formação dos conhecimentos, o reforço dos controles e das resistências, encadeiam-se uns aos outros, segundo algumas grandes estratégias de saber e de poder. (p. 116-117).

Neste sentido, a sexualidade pode ser entendida como uma construção social, cultural e histórica, que foi produzida por um conjunto heterogêneo, ou seja, através de diversos discursos, leis, instituição e instâncias sociais, enunciados etc., permeada por disputas e por relações de poder/saber (FOUCAULT, 2008).

Sendo assim, entendemos que o sexting faz parte desse grande dispositivo histórico da sexualidade, pois está relacionado a desejos, prazeres, saberes e poderes. Também pode ser entendido como uma invenção da contemporaneidade, pois tem sido construído através de diversos discursos. A partir dessa prática, os sujeitos têm como objetivo tornar-se a personalidade do momento, através exibição da sexualidade.

Ao longo deste artigo, tecemos alguns apontamentos teóricos, discutindo sobre a constituição da sociedade do espetáculo. Em seguida, apresentamos as estratégias metodológicas, discutindo sobre o modo como produzimos os dados e as formas de análise. Por fim, analisamos os materiais produzidos sobre o sexting e tecemos algumas considerações deste artigo.

\section{Tecendo alguns apontamentos teóricos}

$\mathrm{Na}$ contemporaneidade, a sociedade está sofrendo algumas modificações e reconfigurações, de forma que o disciplinamento dos corpos, das normas e das condutas, tão vigentes ao longo da modernidade, está dando lugar à transparência, ao efêmero, ao amor-próprio, ao "direito de escolha", à espetacularização, à sedução, à moda etc. Assim, segundo Sébastien Charles (2004), nessa época que estamos vivenciando, não existem 
mais modelos prescritos pelos grupos sociais, e sim condutas escolhidas e assumidas pelos indivíduos; há não mais normas impostas sem discussão, e sim uma vontade de seduzir que afeta indistintamente o domínio público (culto à transparência e à comunicação) e o privado (multiplicação das descobertas e das experiências subjetivas). (p. 24-25).

Os padrões estabelecidos ao longo da modernidade estão mais maleáveis e os sujeitos têm algumas possibilidades de escolha e de expressão.

Todas essas características, como sedução e transparência, por exemplo, deram espaço a outra cultura, que cultua o espetáculo. Segundo Douglas Kellner (2012), “o espetáculo está se tornando um dos princípios organizacionais da economia, da política, da sociedade e da vida cotidiana" (p. 5). Está vinculado à obsessão em se mostrar e, para tanto, são utilizadas diversas estratégias para que os indivíduos possam escancarar sua vida.

Dessa forma, a sociedade do espetáculo está relacionada à produção e disseminação de imagens e sua relação com os diversos sujeitos constituintes de nossa sociedade, pois não basta produzir ou escancarar a vida privada se não houver alguém para ser o/a espectador/a. Assim, para Guy Debord (2012), o espetáculo "não é um conjunto de imagens, mas uma relação social entre pessoas, mediatizada por imagens" (p. 14). Nesse sentido, a sociedade do espetáculo nada mais é do que a procura por se fazer visto, a busca pela aparição.

No entanto, temos que ter o cuidado ao falarmos sobre o surgimento da sociedade do espetáculo, pois não podemos entendê-la como algo novo que surge na contemporaneidade, uma vez que essa configuração social está se formando já faz algum tempo. Para Kellner (2012),

os espetáculos existem desde os tempos pré-modernos. A Grécia Clássica teve seu Olimpo, seus festivais de dramaturgia e de poesia, suas batalhas retóricas públicas, e guerras sangrentas e violentas. A Roma Antiga viveu suas orgias, a ampla oferta de pão e circo, suas grandiosas batalhas políticas e o espetáculo do Império com as paradas e os monumentos em honra dos Césares vitoriosos e de seus exércitos, extravagâncias mostradas em 2000, no filme $O$ Gladiador. E como o historiador alemão Johan Huizinga 
nos lembra, a vida medieval também teve seus momentos marcantes de exibições e espetáculos. (p. 5)

Esse tipo de sociedade vem se constituindo desde os tempos pré-modernos, quando se promoviam espetáculos para se mostrar algo ou alguém para toda a população. Porém, na contemporaneidade, a sociedade do espetáculo apresenta algumas reconfigurações, pois o espetáculo não fica restrito apenas a pessoas ditas "públicas", tais como: atores/atrizes, esportistas, músicos/musicistas etc., mas ele se propaga para o indivíduo "comum"; assim todos nós (eu e vocês) podemos ser protagonistas de espetáculos, ou seja, todos/as podem expor sua vida de forma planetária.

Para aparecer, os indivíduos escancaram para todos/as aquelas vivências do seu cotidiano; assim é a vida real ficcionalizada que é exposta, e é a partir dela que se procura tornar-se a personalidade do momento. Para tanto, tais indivíduos aproveitam-se de algumas tecnologias para ganhar a visibilidade do eu. Para Paula Sibilia (2008), "espetacularizar o eu consiste precisamente nisso: transformar nossas personalidades e vidas (já nem tão) privadas em realidades ficcionalizadas com recursos midiáticos." (p. 197).

Nessa sociedade do espetáculo, vale tudo para aparecer. e são aqueles pensamentos e atitudes mais íntimas que são expostas aos olhos de todos/as. Assim, aquilo que durante muito tempo foi entendido como de âmbito privado - a sexualidade, o corpo, a alimentação, os cuidados com a higiene, entre outros - torna-se algo a ser exposto aos olhos de todos/as, que esperam ávidos/as para conhecer a vida alheia, já que a sociedade do espetáculo não é marcada apenas pela vontade de exibição, mas também pela vontade de saber e conhecer a vida dos/as outros/as (SIBILIA, 2008).

$\mathrm{Na}$ contemporaneidade, podemos perceber um afrouxamento entre as fronteiras do que é permitido para o espaço público e para o espaço privado na sociedade atual. $E$, por esse viés, algumas questões que eram entendidas como de âmbito privado, como a sexualidade, por exemplo, acabam invadindo o âmbito público; assim, a vida privada tornase algo a ser discutida no espaço público, para que todos/as possam ter acesso à vida cotidiana. Para Zygmunt Bauman (2001), “o 'interesse público' é reduzido à curiosidade sobre as vidas privadas de figuras públicas e a arte da vida pública é reduzida à exposição pública das questões privadas e a confissão de sentimentos privados (quanto mais íntimo 
melhor)." (p. 46). Sendo assim, podemos evidenciar que a sociedade não busca mais ocultar ou esconder aquilo que é íntimo e pessoal, mas há sim há uma necessidade de escancarar a vida privada para todos/as; assim, vivemos em uma sociedade em que a vida privada tornase transparente e a vida "real" produzida é exposta ou confessada para todos/as.

A expansão da sociedade do espetáculo, bem como o afrouxamento de fronteiras entre as esferas pública e privada, foram impulsionados pela propagação, evolução e ampla disseminação das tecnologias da informação e da comunicação por toda a sociedade. Se antes apenas pessoas públicas podiam expor suas opiniões e sua vida íntima, e as informações eram produzidas por um determinado polo e transmitidas para toda a população, na contemporaneidade, todos nós podemos produzir e disseminar informações e notícias sobre qualquer situação que desejarmos.

Assim, o desenvolvimento e a popularização de algumas tecnologias, tais como: computadores, sistema Bluetooth, internet, celulares, câmera fotográfica, estão produzindo novas formas de ser e estar em nossa sociedade, possibilitando uma maior democratização da palavra e da constituição da informação, que se torna mais colaborativa e interativa. De acordo com André Lemos e Pierre Lévy (2010):

As chamadas "novas mídias", como a Internet, os telefones celulares, os microcomputadores, assim como os softwares, agentes e inúmeras ferramentas de comunicação, podem desempenhar funções não centralizadoras ou simplesmente massivas, mas abertas, colaborativas, interativas, distributivas... "pós-massivas". (p. 47).

E são essas novas tecnologias digitais pós-massivas que possibilitam interações entre os sujeitos e produzem reconfigurações sociais, culturais e históricas. É a possibilidade de interação com os/as outros/as e de produção de informação que está criando condições para emergência de uma sociedade que busca visibilidade e transparência, e a vida privada agora se torna algo a ser exposto. Segundo Sibilia (2008), "das webcams aos paparazzi, dos blogs e fotologs ao Youtube e ao Orkut, das câmeras de segurança aos reality shows e talk shows, a velha intimidade se transformou em outra coisa. E agora está à vista de todos." (p. 78). 
Nesse contexto de busca pela espetacularização do eu, de afrouxamento entre as fronteiras entre os espaços públicos e privados, e de democratização das tecnologias digitais, emergem novas práticas sociais que buscam a visibilidade. Dentre essas práticas, aparece o fenômeno chamado de sexting, que está diretamente envolvido com as temáticas relacionadas à sexualidade.

O termo sexting foi produzido nos Estados Unidos da América e é resultado da união de duas palavras em inglês: sex (refere-se a sexo) e texting (envio de textos ou mensagens). Tal termo está vinculado ao envio de mensagem de conotação sexual. Segundo SaferNet Brasil (2012), o sexting pode ser entendido como:

um fenômeno recente no qual adolescentes e jovens usam seus celulares, câmeras fotográficas, contas de email, salas de bate-papo, comunicadores instantâneos e sites de relacionamento para produzir e enviar fotos sensuais de seu corpo (nu ou seminu). Envolve também mensagens de texto eróticas (no celular ou Internet) com convites e insinuações sexuais para namorado(a), pretendentes e/ou amigos(as). (s/p).

É importante ressaltar que o sexting não envolve apenas crianças e adolescentes, mas adultos também estão envolvidos com esse fenômeno; assim, tal prática abrange diferentes faixas etárias. Quando o termo foi criado, ele era caracterizado apenas pelo envio de mensagens sexuais através do celular; no entanto, entendemos que outras tecnologias estão sendo utilizadas para essa prática. Hoje, porém, os/as praticantes do sexting utilizamse das diversas tecnologias presentes em nossa sociedade para exporem sua sexualidade. Celulares, smartphones, computadores, câmeras fotográficas, filmadoras, webcams, sites de redes sociais etc. são utilizados por diversos sujeitos (adolescentes e adultos) para a produção de vídeo e fotos eróticas, sensuais e que mostram sexo explícito. Nesse sentido, as tecnologias são utilizadas para a exposição da sexualidade, que, na contemporaneidade, torna-se algo a ser escancarado para todos/as.

Por esse viés, entendemos que o termo sexting discute uma prática social que está se disseminando de forma vertiginosa pela nossa sociedade. Um estudo realizado pela Safernet no Brasil, em 2009, constatou que $12,1 \%$ dos/as adolescentes participantes de uma pesquisa realizada com alunos/as de algumas escolas da rede pública e particular, dos Estados do Rio de Janeiro, Paraíba, Pará e São Paulo, já publicaram fotos íntimas na internet, e nos Estados 
Unidos esse número foi ainda maior, chegou a 20\%, (SEX, 2012). Com tamanha disseminação dessa prática, em 2011, o termo sexting passou a fazer parte do dicionário Oxford.

Pensando na repercussão que o sexting vem tendo em nossa sociedade, nesta pesquisa procuramos analisar algumas reportagens, notícias, blogs, comentários, postados na internet, a fim de investigar as enunciações sobre a espetacularização da sexualidade.

\section{Tecendo os caminhos metodológicos}

Este trabalho é de cunho qualitativo e segue o caminho das pesquisas sociais, que procuram entender e discutir os fenômenos que estão ocorrendo em um determinado contexto sociocultural.

Para tanto, utilizamos a internet para a produção dos dados da pesquisa. Segundo Suely Fragoso, Raquel Recuero e Adriana Amaral (2012), existem três modos de utilizar a internet em nossas pesquisas: a mesma pode ser usada como "objeto de pesquisa (aquilo que se estuda), local de pesquisa (ambiente onde a pesquisa é realizada) e ainda, instrumento de pesquisa (ferramenta para coleta de dados sobre um dado tema ou assunto)." (p. 17). A fim de encontrar materiais, como notícias, reportagens, comentários, postagens, entre outros, utilizamos-nos da internet como um instrumento de pesquisa, que nos possibilitou coletar os dados para o presente estudo.

A procura dos materiais foi realizada através da empresa de serviços on-line chamada Google. A fim de refinar as buscas do material, utilizamos alguns termos-chave, tais como: "sexting", "vídeos de adolescentes postados na internet", "sexo entre adolescentes e internet", "fotos sensuais de adolescentes na internet", "reportagens sobre vídeos de sexo entre adolescentes na internet".

Ao todo, encontramos um total de 48 (quarenta e oito) materiais (reportagens de programas televisivos postados na internet, notícias de jornais, comentários sobre as matérias, reportagens de revistas e blogs, bem como notícias presentes em alguns sites da internet) que discutem de alguma forma a prática do sexting. Desses, 37 (trinta e sete) narravam ou falavam sobre a produção de vídeos caseiros, que exibiam adolescentes mantendo relações sexuais ou trocando carícias íntimas; 8 (oito) falavam de forma ampla sobre essa prática social (trazendo alguns exemplos de situações que envolviam essa prática sexual, sendo que a maioria destacava a produção de vídeos); e 3 (três) abordavam fotos 
sensuais produzidas pelos/as adolescentes. As reportagens que discutiam, de forma geral, sobre o sexting, abordavam algumas questões, tais como: os riscos da internet, os cuidados que os pais/mães devem ter em permitir o uso das tecnologias aos seus/suas filhos/as, os perigos de produzir fotos sensuais, o sexting e a relação com a pornografia, os crimes pornográficos e a ameaça da reputação de quem pratica o sexting. Todos os materiais que serão analisados na pesquisa foram publicados no período de 2008 a 2012.

Neste artigo, analisamos 13 (treze) materiais, tais como: notícias, reportagens e comentários postados por internautas em sites da internet. Os materiais estão divididos em 4 (quatro) blocos: o primeiro apresenta os títulos das notícias, o segundo os das reportagens, o terceiro dos comentários de internautas:

Notícias:

$\checkmark$ Garota de 13 anos se deixa filmar fazendo sexo com 3 adolescentes.

$\checkmark$ Adolescentes aderem ao 'sexting' e postam fotos sensuais na internet.

$\checkmark$ Adolescentes fazem sexo livremente e exibem vídeos na internet como troféus.

$\checkmark$ As imagens de adolescentes fazendo sexo oral chocaram Bom Retiro do Sul (RS).

$\checkmark$ Adolescentes postam fotos sensuais na internet.

$\checkmark$ Aluna quis ser filmada durante sexo.

$\checkmark$ Vídeo de sexo entre alunos no ginásio da escola no Pará acaba na Internet.

\section{Reportagens:}

$\checkmark \quad$ Vídeo com cenas de sexo entre jovens causa polêmica em escola de Belém.

$\checkmark$ Sexo cada vez mais cedo.

$\checkmark$ O uso da internet pelos jovens e suas consequências.

$\checkmark$ Adolescentes filmam relações sexuais para competir na rede.

$\checkmark$ O que cada pai deve saber sobre sexting.

Comentários dos internautas:

$\checkmark$ Confessam terem postado vídeo de sexo oral na internet. 
Para a análise dos dados produzidos, utilizamos algumas ferramentas foucaultianas e, para tanto, investigamos as enunciações presentes nos materiais produzidos, que constituem a prática do sexting na espetacularização da sexualidade, sem procurar aquilo que está oculto ou por detrás de uma determinada enunciação.

A enunciação pode ser uma narrativa, uma foto, uma mensagem, um vídeo, um comentário e etc., que são repetidos em diferentes momentos e de diferentes formas. Quando as enunciações têm algo em comum, ou seja, falam sobre o mesmo objeto e possuem o mesmo sentido, elas formam o enunciado (FISCHER, 2001). Assim "diferentes enunciações podem ser repetições de um enunciado idêntico." (DREYFUS; RABINOW, 2010, p. 58).

Para Foucault, "os enunciados, diferentes em sua forma, dispersos no tempo, formam um conjunto quando se referem a um único e mesmo objeto." (2009, p. 36). Esses conjuntos de enunciados estão apoiados em formações discursivas; e essas estão relacionadas às condições sociais, históricas, culturais, políticas e econômicas que a sociedade está vivenciando. São os conjuntos de enunciados, ancorados em uma determinada formação discursiva, que formam um determinado objeto, ou seja, que estão constituindo um determinado discurso.

\section{Analisando as enunciações sobre o sexting: a espetacularização da sexualidade}

Ao analisar o material empírico, podemos perceber que é crescente o número de casos que envolvem o fenômeno do sexting. Assim, fotos de meninas e meninos nus/as e seminus/as, vídeos de relação sexual, mensagens eróticas vêm se tornando parte da vida de alguns/algumas adolescentes na contemporaneidade. Como podemos evidenciar nos excertos abaixo:

É cada vez mais frequente a inserção de imagens de nu e seminu de adolescentes na internet. Muitas dessas fotografias são postadas pelos próprios jovens (ADOLESCENTES, 2012a).

Garota de 13 anos se deixa filmar fazendo sexo com 3 adolescentes (GAROTA, 2012).

Adolescentes aderem ao 'sexting' e postam fotos sensuais na internet (TOMAZ, 2012). 
Muitos não calculam o real alcance do que cai na rede. "Eles confundem público com privado, vivem na era da imagem e acabam se comprometendo demais" (SEXO, 2012). No Paraná, no principal colégio do Estado, as cenas de sexo entre uma aluna e dois estudantes foi no banheiro. Agora, em Belém, a situação se repete, mas apenas entre um casal de alunos, filmado no ginásio do colégio por um outro estudante enquanto mantinham relações (VÍDEO, 2012a).

Através dessas enunciações, percebemos que, em nossa sociedade, vem ocorrendo um afrouxamento do que é considerado de âmbito público e privado, e o que antes era considerado privado, como a sexualidade, por exemplo, torna-se algo a ser mostrado e escancarado para todos/as. Assim, os/as adolescentes praticantes do sexting utilizam-se das diversas tecnologias digitais e da web 2.0 para exporem suas vidas privadas e/ou íntimas. Nesse sentido, a sexualidade torna-se um espetáculo, e é exibida para quem quiser ver. Por meio da exposição do corpo e da sexualidade, os/as protagonistas do sexting promovem um verdadeiro "show do eu" ao exporem sua vida íntima: "Fazendo da própria personalidade um espetáculo; isto é, uma criatura orientada aos olhares dos outros como se estes constituíssem a audiência de um espetáculo." (SIBILIA, 2008, p. 258).

No entanto, não basta apenas expor a vida íntima; o que alguns/algumas desses/as adolescentes praticantes do sexting desejam é o reconhecimento e estar em cena para muitos sujeitos. Para tanto, os/as adolescentes fazem apostas (que esquentam quanto mais audiência possuem) e participam de competições on-line. Tais jogos sexuais têm como propósito ganhar visibilidade através da exibição da sexualidade, como evidenciamos nas enunciações a seguir:

Recentemente, o caso de dois adolescentes gaúchos de classe média, uma menina de 14 e um menino de 16 anos, que transmitiram cenas íntimas ao vivo concordando em tirar as roupas, conforme aumentasse a audiência da transmissão. As imagens foram assistidas por 26 mil usuários, e foram feitos 12 mil downloads do vídeo. 0 garoto, que virou ídolo virtual da noite para o dia, se vangloriou do ocorrido e respondia a perguntas de uma legião de adolescentes (O USO, 2012).

Recebemos várias denúncias de concursos de vídeos no YouTube. Os adolescentes registram as relações sexuais entre eles, colocam no site e fazem uma competição para 
ver qual vídeo tem mais acessos, qual é o vídeo mais assistido. Tivemos casos de vídeos com 400 mil execuções - conta o presidente da SaferNet, Thiago Tavares (ADOLESCENTES, 2012c).

Neste universo, do sexting, ganha fama quem tiver mais acessos no seu fotolog, Orkut e YouTube. Outra maneira de ser popular é vencer os concursos virtuais promovidos pelos sites. Depois disso, a celebridade instantânea irá contar com fã-clubes e uma legião de seguidores [grifos das autoras] (TOMAZ, 2012).

Através dessas enunciações, evidenciamos que essa vontade de aparecer vem sendo expandida em nossa sociedade. Assim, a internet tem sido utilizada como um confessionário, que está servindo para os sujeitos confessarem, narrarem e exibirem a vida privada de qualquer um que queira aparecer. Quando falamos em confissão, não nos dirigimos àquela que era realizada ao longo da modernidade, de forma íntima e privada, mas nos remetemos a essa reconfiguração pela qual a confissão passou, deslocando-se do espaço privado para o público, deixando de ser realizada para sujeitos específicos, para ser realizada para uma multidão de pessoas. Assim, de acordo com Bauman (2008), celulares, smartphones, internet, sites de redes sociais entre outros, podem ser considerados "confessionários eletrônicos", pois eles permitem a cada usuário expor o que quiser para todos/as (p. 10).

Sites e redes sociais vêm sendo utilizados ainda como campos de disputa, em que são criadas estratégias para ganhar cada vez mais visibilidade. Segundo Rose Rocha e Gisela Castro (2009), "as dinâmicas de visibilização incessante configuram verdadeiras arenas de disputa pela conquista de atestados de existência midiáticos. Nessas arenas do visível, homens e mulheres buscam, a todo custo, manter-se em cena." (2009, p. 52).

A democratização das tecnologias digitais vem possibilitando a todos nós colocarmos o que quisermos à disposição dos/as outros/as. Esse contexto vem permitindo uma grande e incessante publicação da vida íntima. É essa expansão das tecnologias digitais que serviu como condição de possibilidade para o surgimento dessas disputas e jogos sexuais, que procuram escancarar as minúcias sexuais. Para Sibilia (2008), as tecnologias digitais, assim como a web 2.0, gerou um "verdadeiro festival de 'vidas privadas', que se oferecem despudoradamente aos olhares do mundo inteiro" (p. 27). Dessa maneira, a postagem de 
fotos sensuais/eróticas e vídeos que mostram carícias e relações sexuais, podem ter um alcance longínquo e global.

Toda essa disputa para aparecer tem como objetivo o uso da imagem pessoal para conquistar a tão sonhada fama; assim essas tecnologias interativas e colaborativas possibilitam que qualquer sujeito possa tornar-se a celebridade ou a personalidade do momento, que é a marca da sociedade do espetáculo. De acordo com Bauman (2011), ser famoso é hoje um dos modos de vida que vem se estabelecendo e se disseminando em nossa sociedade.

Outro ponto de destaque nos materiais analisados está relacionado ao vínculo entre o sexting e a vontade de virar celebridade. Esses materiais sugerem que a prática do sexting está relacionada ao desejo de ser aceito/a, de ganhar visibilidade, de ser reconhecido/a e ter um momento de fama. Podemos evidenciar isso nas enunciações a seguir:

Esse tipo de conduta representa a confusão de conceitos por que passa o adolescente hoje em dia, em busca, principalmente, de aceitação e fama (ADOLESCENTES, 2012a). Meninas e meninos de 12 a 17 anos buscam fama virtual em sites (TOMAZ, 2012). Adolescentes fazem sexo livremente e exibem vídeos na internet como troféus (ADOLESCENTES, 2012b).

Talvez isso (sexting) seja até uma compensação por uma ausência de visibilidade em casa. Se ele não se sente visível, vai procurar ser de alguma forma. Mas procura, em geral, da maneira caricatural (BARROS, 2012).

Em busca de fama na Internet meninos e meninas de 12 a 17 anos postam fotos sensuais na Internet (CASSANTI, 2012).

Com os hormônios à flor da pele e estimulados pelos apelos midiáticos dos realities shows, sinalizam que querem ser vistos e reconhecidos. Assim, tornam suas experiências sexuais um espetáculo na rede (O USO, 2012).

Com essa necessidade de ganhar a fama e de ser reconhecido/a, ou seja, de espetacularizar o eu, esses/as adolescentes acabam transformando-se em mercadorias, mas não têm o desejo de se tornar uma mercadoria qualquer, que seja invisível ao olhar do consumidor. Segundo Bauman (2008), nessa sociedade de consumidores/as existe o desejo da fama e 
de não mais se dissolver e permanecer dissolvido na massa cinzenta, sem face e insípida das mercadorias, de se tornar uma mercadoria notável, notada e cobiçada, uma mercadoria comentada, que se destaca da massa de mercadorias, impossível de ser ignorada, ridicularizada ou rejeitada. (p. 22).

Nesse sonho de tornar-se alguém conhecido/a e reconhecido/a por todos/as, tudo se torna algo a ser mostrado e escancarado para todos/as, inclusive a sexualidade. Assim, podemos entender o sexting como uma prática de consumo, pois a sexualidade é transformada em uma mercadoria, e é através da exibição dela que os/as adolescentes conseguem ganhar visibilidade. Nesse contexto, em que não se busca mais ser ou ter algo, mas sim aparecer, ocorre a "ascensão de um tipo de subjetividade cada vez mais espetacularizada, o triunfo de um modo de vida inteiramente baseado nas aparências e a transformação de tudo em mercadoria." (SIBILIA, 2008, p. 268).

Mediante a investigação do material de pesquisa, evidenciamos uma crescente curiosidade na vida alheia, uma vontade de saber os detalhes, as repercussões, de emitir julgamentos, sobre a vida dos outro/as. Como podemos notar nas enunciações abaixo:

Cadê a fotinho do "casal"? Cadê a fotinha dos papais do "casal"? (ADOLESCENTES, 2012c).

Eu vi esse vídeo e achei um absurdo a proporção de como ele se espalhou pela internet e pelo Bluetooth de milhares de celulares, eu mesma vi no celular de um empacotador dentro de um supermercado (ADOLESCENTES, 2012c).

Logo depois da veiculação do vídeo, eles começaram a receber bilhetes por baixo da porta com insultos. Até pedras foram arremessadas em direção a sua casa (SEXO, 2012). Outros alunos tiveram acesso ao vídeo, que foi parar na internet. No início, os adolescentes fizeram piadas. Mas, agora, demonstram indignação. “O colégio vai ficar mal falado e os alunos ficam mal vistos, parece que não querem estudar. Isso é chato", diz um deles (VÍDEO, 2012b).

As imagens de sexo explícito chocaram a pequena cidade, a $200 \mathrm{~km}$ de Porto Alegre (RS) (IMAGENS, 2012). 
A história tornou-se pública no bairro na semana passada, quando um grupo de jovens do mesmo bairro, estavam acessando a internet em uma lan house e reconheceu os integrantes do vídeo (GAROTA, 2012).

$\mathrm{O}$ vídeo está correndo a internet através de e-mails. As cenas também se espalharam, principalmente entre os jovens, através de celulares equipados com o sistema Bluetooth (ALUNA, 2012).

Tais fragmentos nos remetem a Debord (2012), pois esse autor defende que a sociedade do espetáculo não está relacionada apenas à vontade de aparecer e de se mostrar, mas está vinculada à vontade de saber. Assim, está se constituindo uma cultura que busca saber nos mínimos detalhes o que está acontecendo na vida dos outros sujeitos. Existe assim uma necessidade de examinar e esquadrinhar a vida alheia. Segundo Sibilia (2008): "Uma intensa 'fome de realidade' tem eclodido nos últimos anos, um apetite voraz que incita ao consumo de vidas alheias e reais." (p. 34).

Se ao longo da modernidade o interesse dos sujeitos estava relacionado à vida de pessoas públicas e conhecidas e a histórias literárias, na contemporaneidade o interesse volta-se à vida cotidiana e real de pessoas comuns. É nesse cenário que vem se constituindo uma legião de pessoas que desejam assistir ao espetáculo da vida alheia.

\section{Enfim...}

Realizar a análise do material empírico possibilitou-nos entender o sexting, como uma prática sociocultural, que está vinculada à sociedade do espetáculo, já que o sexting é entendido como uma prática em que os sujeitos usam suas imagens (eróticas, sexuais e sensuais) para a conquista de visibilidade e da espetacularização do eu.

A prática de expor a sexualidade, através de fotos sensuais, mensagens eróticas e vídeos que expõem relações sexuais, por meio de celulares, e-mails, sites de redes sociais etc., que vem se expandindo em nossa sociedade, pode ser entendida como um verdadeiro "show do eu" (SIBILIA, 2008).

No entanto, não é por acaso que práticas, como a do sexting, que buscam espetacularizar o eu, emergem nesse momento em nossa sociedade. Essa vontade de 
aparecer está vinculada com a lógica do mercado, em que tudo se transforma em um bem de consumo. Para Bauman (2008):

\begin{abstract}
$\mathrm{Na}$ sociedade de consumidores, ninguém pode se tornar sujeito sem primeiro virar mercadoria, e ninguém pode manter segura sua subjetividade sem reanimar, ressuscitar e recarregar de maneira perpétua as capacidades esperadas exigidas de uma mercadoria vendável. (p.20).
\end{abstract}

Nesse cenário, em que a sexualidade torna-se uma mercadoria que entra na lógica do consumo, a mesma é produzida e exposta, a fim de os sujeitos conquistarem fama, ou seja, o sexting está relacionado à vontade de seus/suas praticantes tornarem-se as "celebridades" do momento. Assim, a sexualidade torna-se um produto a ser vendido/oferecido em troca do sucesso.

Mas se existe uma vontade desses sujeitos em adquirir fama e reconhecimento, existem também consumidores/as ávidos/as por conhecerem a vida íntima dos/as praticantes do sexting. Assim, essa lógica consumista, de querer se exibir e de querer consumir a vida alheia, é o que vem mantendo essa sociedade do espetáculo.

Investigar a prática do sexting tem nos possibilitado conhecer e entender a emergência de uma sociedade que está ocupada e preocupada com o "mercado das aparências" (SIBILIA, 2008). Por isso, consideramos que este trabalho contribui para entendermos esse fenômeno recente, chamado de sexting, bem como a sua relação com a sociedade do espetáculo.

\title{
Referências
}

ADOLESCENTES postam fotos sensuais na internet. Disponível em: $<$ http://www.andi.org.br/infancia-e-juventude/noticia-clipping/adolescentes-postam-fotossensuais-na-internet>. Acesso em: 15 set. 2012a.

ADOLESCENTES fazem sexo livremente e exibem vídeos na internet como troféus. Disponível em: <http://routenews.com.br/index/?p=6386>. Acesso em: 15 set. 2012b. 
ADOLESCENTES confessam terem postado vídeo de sexo oral na internet. Disponível em: $<$ http://www.saocarlosagora.com.br/cidade/noticia/2011/11/18/24202/adolescentesconfessam-terem-postado-video-de-sexo-oral-na-internet/?page=8>. Acesso em: 15 set. 2012c.

ALUNA quis ser filmada durante sexo. Disponível em: <http://youpode.com.br/?p=37315\#more-3731523.02.1115H06M>. Acesso em: 16 set. 2012.

BARROS, Ana Cláudia. Adolescentes filmam relações sexuais para competir na rede. Disponível em: <http://entretenimientoar.terra.com.ar/oscar/2009/interna/0,,014572453El6594.html>. Acesso em: dia jun. 2012.

BAUMAN, Z. Modernidade líquida. Rio de Janeiro: Zahar, 2001.

44 Cartas do mundo líquido moderno. Rio de Janeiro: Zahar, 2011.

Vida para consumo: a transformação das pessoas em mercadorias. Rio de Janeiro: Zahar, 2008.

CASSANTI, Moises de Oliveira. 0 que cada pai deve saber sobre sexting. Disponível em: <http://www.crimespelainternet.com.br/o-que-cada-pai-deve-saber-sobre-sexting/>. Acesso em: 30 jun. 2012.

CHARLES, Sébastien. O individualismo paradoxal: introdução ao pensamento de Gilles Lipovetsky. In: LIPOVETSKY, Gilles. Tempos Hipermodernos. São Paulo: Barcarolla, 2004. p. 11-48.

DREYFUS, H.; RABINOW, P. Michel Foucault: uma trajetória filosófica. para além do estruturalismo e da hermenêutica. Rio de Janeiro: Forense Universitária, 2010.

DEBORD, G. A Sociedade do Espetáculo. Disponível em: <http://www.cisc.org.br/portal/biblioteca/socespetaculo.pdf>. Acesso em: 30 jul. 2012.

FISCHER, R. M. B. Foucault e a Análise do discurso em educação. Cadernos de Pesquisa, São Paulo, n. 114, p. 197-223, nov. 2001.

FOUCAULT, M. A arqueologia do saber. 7.ed. Rio de Janeiro: Forense Universitária, 2009.

História da sexualidade: a vontade de saber. 18. ed. Rio de Janeiro: Graal, 2007.

Sobre a história da sexualidade. In: Microfísica do poder. 25. ed. Rio de Janeiro: Graal, 2008. p. 243-276. 
FRAGOSO, S.; RECUERO, R.; AMARAL, A. Métodos de pesquisa para internet. Porto Alegre: Sulina, 2012.

GAROTA de 13 anos se deixa filmar fazendo sexo com 3 adolescentes. Disponível em: <http://180graus.com/noticias/garota-de-13-anos-se-deixa-filmar-fazendo-sexo-com-3adolescentes-244880.html >. Acesso em: 15 set. 2012.

IMAGENS de adolescentes fazendo sexo oral chocam Bom Retiro do Sul (RS). Disponível em: $<$ http://noticias.r7.com/videos/imagens-de-adolescente-fazendo-sexo-oral-chocam-bomretiro-do-sul-rs-/idmedia/67296a8939929e2074ba01e812fd0571.html>. Acesso em: 20 set. 2012.

KELLNER, D. A cultura da mídia e o triunfo do espetáculo. Disponível em: <http://200.144.189.42/ojs/index.php/libero/article/viewFile/3901/3660>. Acesso em: 20 set. 2012.

LEMOS, A.; LÉVY, P. O futuro da internet: em direção a uma ciberdemocracia planetária. 2. ed. São Paulo: Paulus, 2010. (Coleção Comunicação).

ROCHA, R.; CASTRO, G. Cultura da mídia, Cultura do consumo: Imagem e espetáculo no discurso pós-moderno. LOGOS 30: Tecnologias de Comunicação e Subjetividade, Rio de janeiro, ano 16, 1ㅇs. 2009.

SAFERNET Brasil. Banner: Você navega com segurança? Disponível em: <http://divulgue.safernet.org.br/banners/infografico.png>. Acesso em: 20 jul. 2012.

SEX and tech. Results from a survey of teens and Young adults. Disponível em: <http://www.thenationalcampaign.org/sextech/PDF/SexTech_Summary.pdf>. Acesso em: 15 set. 2012.

SEXO cada vez mais cedo. Disponível em: <http://www.istoe.com.br/reportagens/10862_SEXO+CADA+VEZ+MAIS+CEDOSexo\%20cada \%20vez\%20mais\%20cedo\%20Reportagem\%20isto\%C3\%A9>. Acesso em: 20 set. 2012.

SIBILIA, P. O show do eu: a intimidade como espetáculo. Rio de Janeiro: Nova Fronteira, 2008.

TOMAZ, Kleber. Adolescentes aderem ao 'sexting' e postam fotos sensuais na internet. Disponível em: <http://g1.globo.com/sao-paulo/noticia/2010/05/adolescentes-aderem-aosexting-e-postam-fotos-sensuais-na-internet.html>. Acesso em: 15 set. 2012.

O USO da internet pelos jovens e suas consequências. Disponível em: <http://acritica.uol.com.br/vida/Comportamento-Pais_e_Filhos_0_356364435.html>. Acesso em: 20 set. 2012. 
VÍDEO de sexo entre alunos no ginásio da escola no Pará acaba na Internet. Disponível em: <http://youpode.com.br/?p=25575>. Acesso em: $18 \mathrm{dez}$. 2012a.

VÍDEO com cenas de sexo entre jovens causa polêmica em escola de Belém. Disponível em: $<$ http://www.saiunojornal.com.br/video-com-cenas-de-sexo-entre-jovens-alunos-causapolemica-em-escola-de-belem-menore.html>. Acesso em: 20 set. 2012 b.

Enviado em Abril/2013 Aprovado em Outubro/2013 